\title{
Intelligent Systems based Selective Harmonic Elimination (SHE) for Single Phase Voltage SOURSE Inverter
}

\author{
Basil M. Saied \\ Elect. Eng. Dept \\ University of \\ Mosul
}

\author{
Qais M. Alias \\ Elect. \& Electronic Eng. \\ Dept \\ University of Technology
}

\author{
Ahmed S. AL-soufy \\ Elect. Eng. Dept \\ University of Mosul
}

\begin{abstract}
Pulse Width Modulation (PWM) inverters are of huge and great impact in many engineering disciplines. It plays a big role in the field of power electronics regarding voltage sources to vast amount of electronics equipments and machine controllers. The use of artificial intelligence in gate signals control in PWM voltage source inverter (VSI) is tackled, analyzed, and implemented in this paper. The PWM technique that investigated in this work is the Selective Harmonic Elimination (SHE). For this technique, the single phase H-bridge inverter is considered for the study. In the SHE based inverter, the fundamental voltage level and the harmonics selected for deletion are decided using a neural network ad fuzzy logics. For the SHE technique, the results of generating switching angle patterns, using the neural and the fuzzy model controllers, for driving H-bridge inverter, show almost exact resemblance, compared to those obtained using conventional controllers. Also the superiority at the intelligent models overcome the problem of delay time and have fast response in selecting and generating the PWM patterns required to regulate the inverter output voltage.
\end{abstract}

Keywords: H-bridge inverter, Pulse Width Modulation, Selective Harmonic Elimination, Intelligent Techniques.

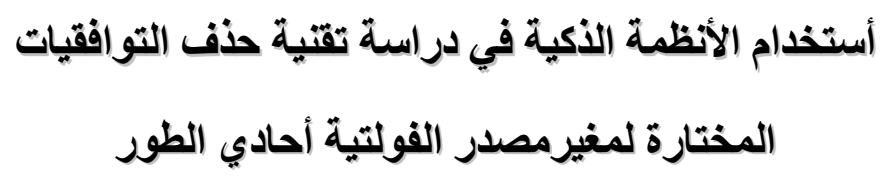



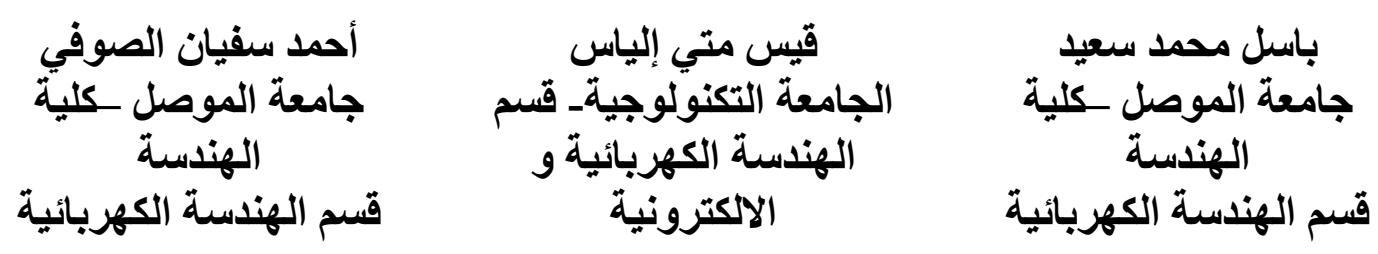

\section{الخلاصة}

إن مغير ات تضمين عرض النبضـة ذات تأثير واسع في العديد من الار اسـات الهندسية. وهي

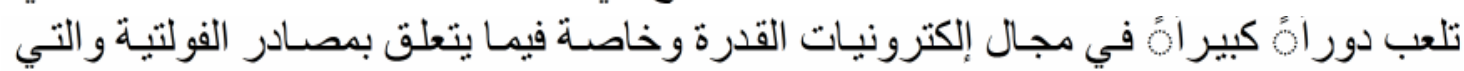
ات الإلكترونية ومتحكمات الماكنة.

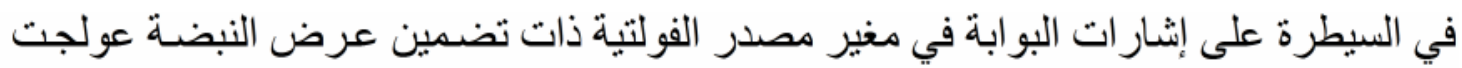

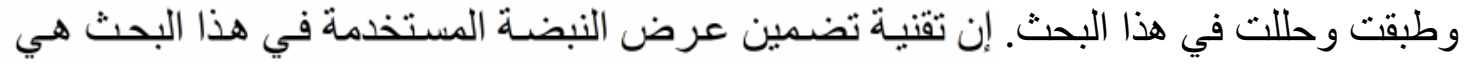

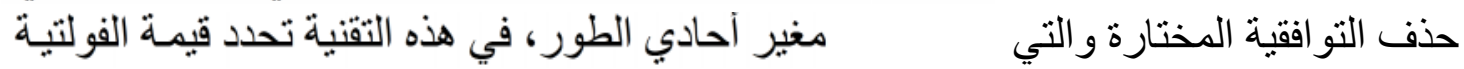

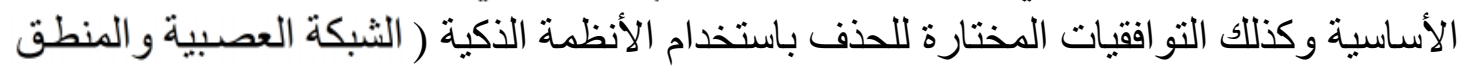

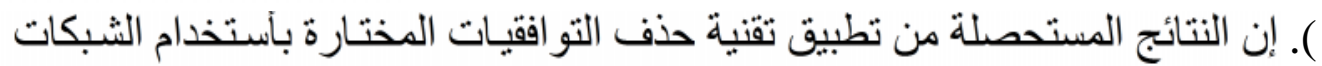

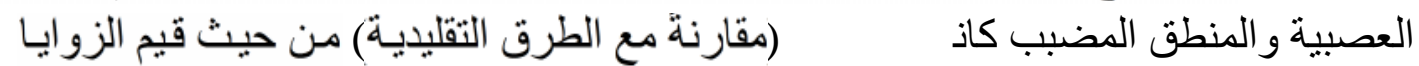

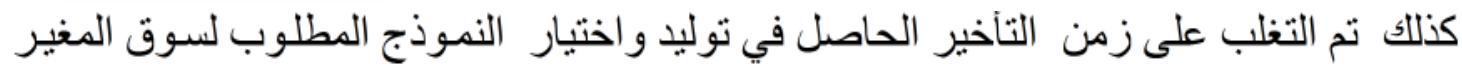

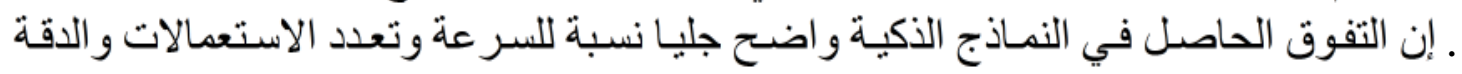
و و التكيف للتغير.

\section{Introduction}

In the past few decade the power electronics field witnessed a rapid growth in power semiconductors and digital techniques, which makes it possible to build systems with high efficiency, reliable and low cost. One of these systems is the voltage source inverter (VSI), which is used in different fields of power converters such as UPS, SMPS, drives, tractions and HVDC [1]. VSI is used to convert DC supply to AC supply at required number of phases and values of voltage and frequency. Different methods were used to generate the gate signals for switching the semiconductor power swiching devices in the inverter. The most 
effective method is the PWM that has ability to regulate the magnitude and frequency of inverter output voltage, and also eliminating or minimizing significant harmonic components of the output voltage. This kind of VSI, based on PWM method, can be performed using different types of strategies. The main types are; natural sampling, suboptimal, optimal and harmonic elimination strategies. Each one of these types depends on an algorithm that generates the PWM patterns which are used to drive the inverter swiching power devices [2].

The most effective type is selected harmonic elimination (SHE) technique, which eliminates selected low order harmonics from the spectrum and also reduces the total harmonic distortion (THD) [3]. In fact, in order to obtain PWM patterns, number of nonlinear equations in terms of unknown switching angles, depend on number of harmonic components to be eliminated, have to be solved for each value of modulation index using numerical minimization approach. These can be achieved in off line and stored as look up tables. Due to the nature of nonlinearity between the switching angles and the fundamental of the PWM, a large number of look up tables are needed. These tables are stored in a programmable memory and using for example, microcomputer or microcontroller board which has been programmed to accept the value of modulation index and generate the corresponding switching angles. The problems of the conventional methods are the off line look up tables calculations, the selection values of PWM pattern, or using the analog and digital hardware because the solution of the equations for solving switching angles is difficult in on-line [4,9]. The hardware needs a large look up tables to store the information of switching angles of SHE-PWM technique. Therefore a propose techniques are applied by using the intelligent methods (neural network and fuzzy logic). The intelligent methods are useful for this case because they represent nonlinear and complex models and apply this concept by simulating it with MATLAB/SIMULINK program, Moreover the time requirement to achieve this process is suitable for on line.

\section{Modulation index and the switching angles for (SHE)}


The idea of (SHE) based on chopping the square-wave output many times to eliminate the effective lower order harmonics, and also to control and regulate the fundamental voltage. Fig.1 shows a general inverter output voltage waveform with $\mathrm{N}$ chops per quarter-cycle [4].

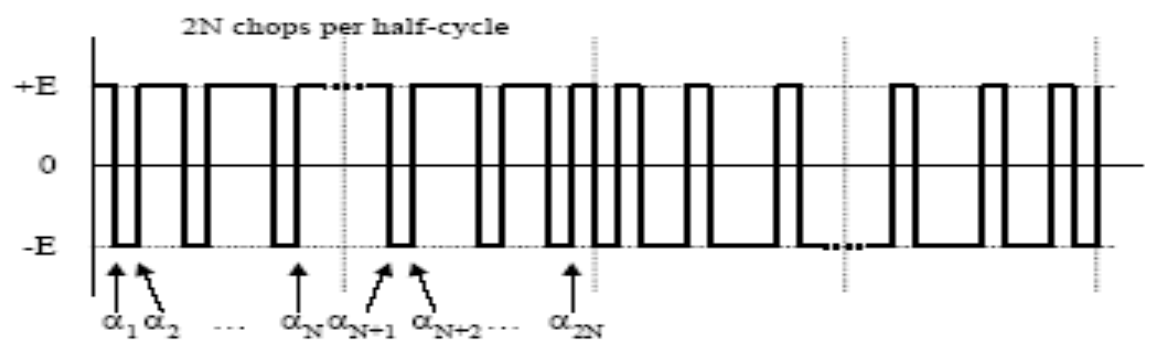

Fig.1: Waveform of a 2-level SHE PWM

It is assumed that the periodic waveform has quarter-wave and half-wave symmetry, i.e.

$$
\begin{aligned}
& \alpha_{N+1}, \alpha_{N+2}, \alpha_{N+3}, \ldots, \alpha_{2 N}=\left(\pi-\alpha_{N}\right),\left(\pi-\alpha_{N-1}\right),\left(\pi-\alpha_{N-2}\right), \ldots,\left(\pi-\alpha_{1}\right) \quad \boldsymbol{\&} \\
& \alpha_{2 N+1}, \alpha_{2 N+2}, \ldots \alpha_{3 N}, \alpha_{3 N+1}, \alpha_{3 N+2} \ldots \alpha_{4 N}=\pi+\alpha_{1}, \pi+\alpha_{2}, \ldots \pi+\alpha_{N}, \pi+\alpha_{N+1}, \pi+\alpha_{N+22}, \ldots \pi+\alpha_{2 N}
\end{aligned}
$$

To obtain the amplitude of each harmonic content, Fourier series is applied, and the final result is given as [4]:

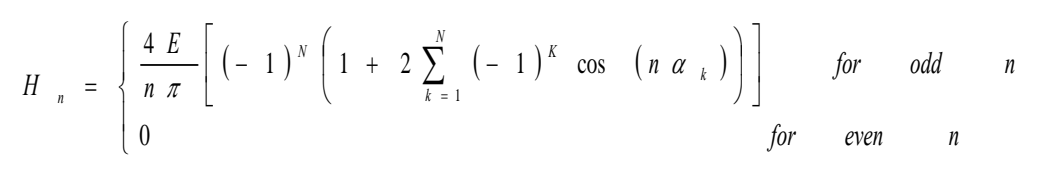

Where ' $\mathrm{N}$ ' is the number of switching angles (chops) per quarter cycle, ' $\mathrm{n}$ ' is the harmonic order. Equation 2 shows that the fundamental output voltage can be selected and 'n' effective low order harmonics can be eliminated (i.e. $3^{\text {rd }}, 5^{\text {th }}, 7^{\text {th }} \ldots$..etc.) from single-phase output waveform. This is achieved by solving the $N$ 's equations as: 


$$
\begin{aligned}
& H_{1}(\alpha)=M . E \\
& H_{k}(\alpha)=0
\end{aligned}
$$

Where ' $\mathrm{M}$ ' is the modulation index, $\mathrm{E}$ is the DC supply voltage, and ' $\mathrm{k}=3,5,7 . . \mathrm{n}$ ' is the order of eliminated harmonic components. Notice that in the natural sinusoidal PWM strategy, a large number of switching is required, with the consequent increase of switching losses. With the method of Selective Harmonic Elimination, only selected harmonics are eliminated with the smallest number of switching. This method however is difficult to be implementing on-line due to computations and memory requirements and needs to solve a set of complex nonlinear equations. In a two level PWM single phase full bridge controlled inverter, with odd harmonics and half wave symmetries waveform and $\mathrm{N}$ chops per quarter cycle which is shown in Fig.(1), The magnitude of the harmonic components including the fundamental, are given by:

$$
\begin{aligned}
& \mathrm{H}_{1} / \mathrm{E}=-(4 / \pi) .\left[1-2 \cos \alpha_{1}+2 \cos \alpha_{2}-2 \cos \alpha_{3} \ldots \ldots .2 \cos \alpha_{N}\right]=\mathrm{M} \\
& \mathrm{H}_{3} / \mathrm{E}=-(4 / 3 \pi) .\left[1-2 \cos 3 \alpha_{1}+2 \cos 3 \alpha_{2}-2 \cos 3 \alpha_{3} \ldots 2 \cos 3 \alpha_{N}\right]=0 \\
& \cdot \\
& \cdot \\
& \mathrm{H}_{\mathrm{n}} / \mathrm{E}=-(4 / \mathrm{n} \pi) . \quad\left[1-2 \cos n \alpha_{1}+2 \cos n \alpha_{2}-2 \cos n \alpha_{3} \ldots 2 \cos n \alpha_{N}\right]=0
\end{aligned}
$$

Where $\mathrm{H}_{\mathrm{n}}$ is the magnitude of the $\mathrm{n}^{\text {th }}$ harmonic (odd harmonics) and $\mathrm{N}$ is number of chops per quarter cycle, and therefore $\mathrm{N}$ number of nonlinear equations, for each value of index $\mathrm{M}$, need to be solved. In the above equations, the desired values is zero for the total number of (N-1) harmonic components to be eliminated and the desired per-unit AC magnitude for the fundamental and the solution aim for the $\alpha$ 's angles.

Also $\alpha_{N}$ must satisfy the following condition:

$$
\alpha_{1}<\alpha_{2}<\ldots<\alpha_{N}<\pi / 2
$$


Other switching angles will be obtained by symmetry as given in equation (1).

\section{Applying the Neural Network Method}

The implementation of the feed forward neural network based SHE (Programmed PWM) in single phase voltage source inverter is interesting and it makes the neural network controls the magnitude of fundamentals harmonic $\left(\mathrm{H}_{1}\right)$ easier in case that its value changes and returns it to a desired value. The feed forward neural network accepts modulation index as input, and gives the outputs as primary switching angles, the secondary switching angles can easily be produced from the primary ones [10]. The neural network used has one input neuron and $\mathrm{N}$ output neurons (to produce $\mathrm{N}$ switching angles) and here in this research use six as example i.e. $\mathrm{N}=6$ to eliminate five selected harmonics which their order are $3^{\text {rd }}, 5^{\text {th }}$ $, 7^{\text {th }}, 9^{\text {th }}, 11^{\text {th }}$ for $\mathrm{N}=6$. It also fixes the modulation index to a desired value. Different numbers of hidden neurons have been tested; the neural network has sigmoid characteristics and bias. The training set for the network has been produced off-line solving the magnitude of harmonics equations for two hundred values of $\mathrm{M}$ with 0.005 steps from 0.01 to 1 . This means that for each value of $\mathrm{M}$ gives a PWM pattern of switching. See the Appendix for samples of data for switching angels, with corresponding modulation indexes, which are obtained using microcomputer off line calculations. Therefore, it will be possible to get the training set from solving these nonlinear equations by writing a program contains the algorithm to solve these equations in $\mathrm{M}$-file in MATLAB SYSTEM which in turn makes the process fast and easy. The design of the feed forward neural network proposed in this work consists of three layers, as shown in Fig. 2. These layers are: input layer, which has one neuron received the value of $\mathrm{M}$ as input to the proposed circuit, and hidden layer in which the number of neurons depend on the complexity of the application and the speed of the process to reach the minimum Mean Square Error (MSE) between the output and the desired 
value as shown in Fig.3, and output layer which has six neurons to represent the six switching angles and transfer it to firing circuit .

It is assumed that the input training set $(\mathrm{P})$ are the modulation index $\mathrm{M}$ which is used as input to the neural network, while output, target training set $(\mathrm{T})$ are the switching angles $\left(\alpha_{1}, \alpha_{2}, \alpha_{3}, \ldots, \alpha_{\mathrm{N}}\right)$ and implementing them as supervised learning rule in the neural network and can explain them to be:

$\mathrm{P}=\left[\mathrm{M}_{1}, \mathrm{M}_{2}, \mathrm{M}_{3}, \ldots \ldots . ., \mathrm{M}_{\mathrm{i}}\right]$ where $\mathrm{i}$ is the number of modulation index values used in the training.

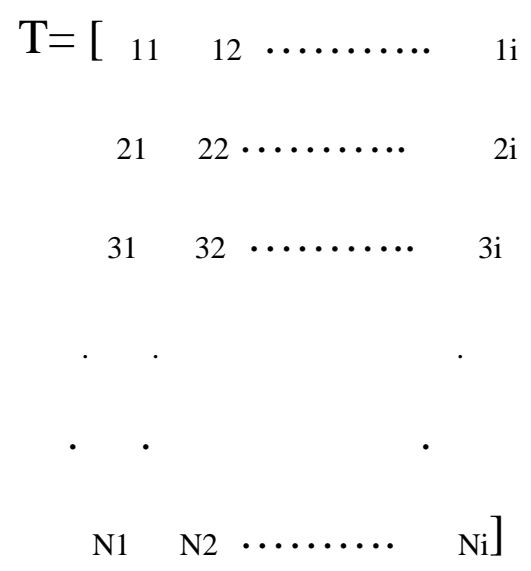

(6)

where $\mathrm{i}$ is the number of groups contain switching angles values.

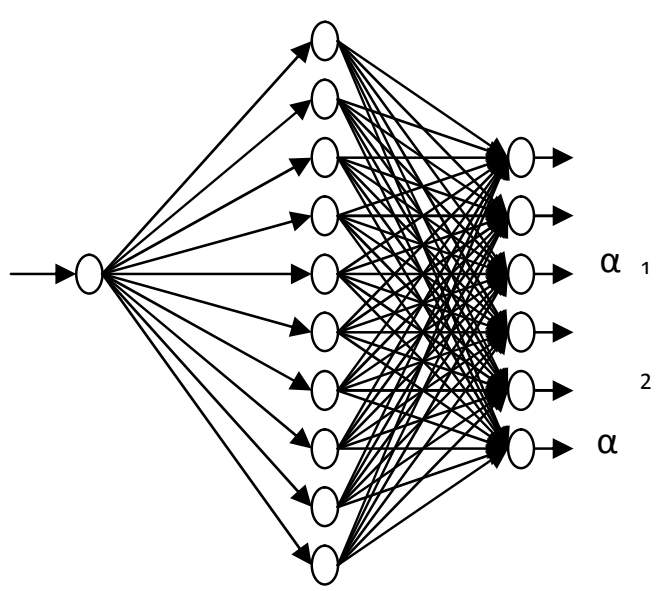


Fig. 2 : The neural network diagram with three layers for six switching angles.

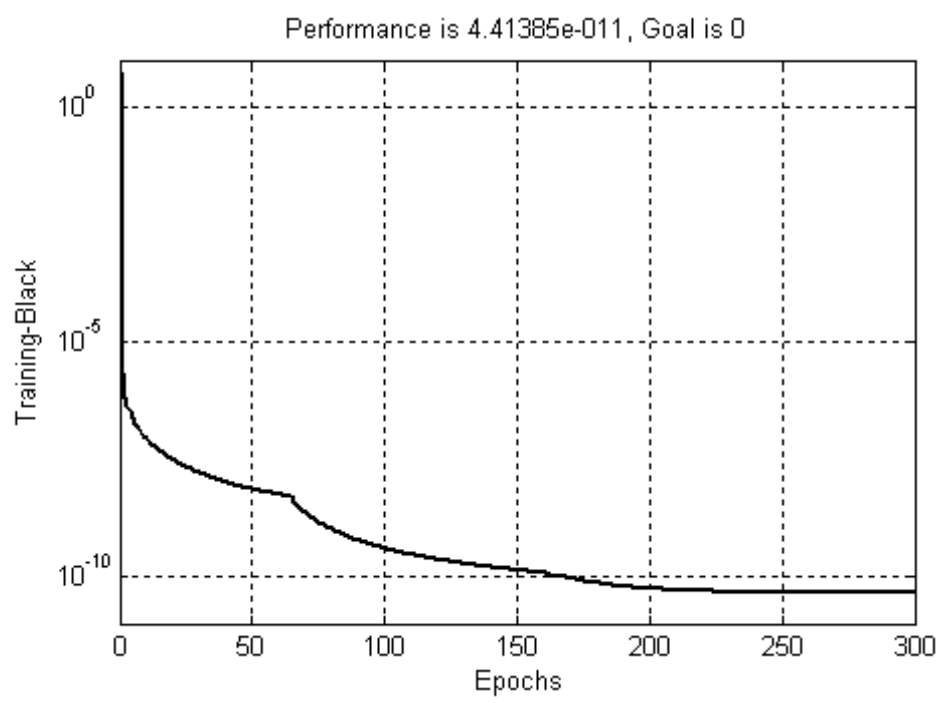


Fig. 3: The MSE for training epochs for neural network

The design of the neural network with the single phase full bridge inverter can be done by MATLAB/SIMULINK as shown in Fig. 4. In this model, it is assumed that the DC voltage source is $100 \mathrm{~V}$ and the inverter is full bridge inverter with MOSFET switch and the with RL load of $\mathrm{R}=10$ and $\mathrm{L}=10 \mathrm{mH}$. The neural network chip is considered to accept one input (Modulation index) and generates six outputs (switching angles), and have firing circuit to generate firing signals for the inverter depending on the switching angles values. Figs. (5 \& 6) show the voltage and current output of the inverter with the value of $M=0.8$ and their Fast Fourier Transform (FFT) spectrum for the six switching angles circuit in the off-line state.

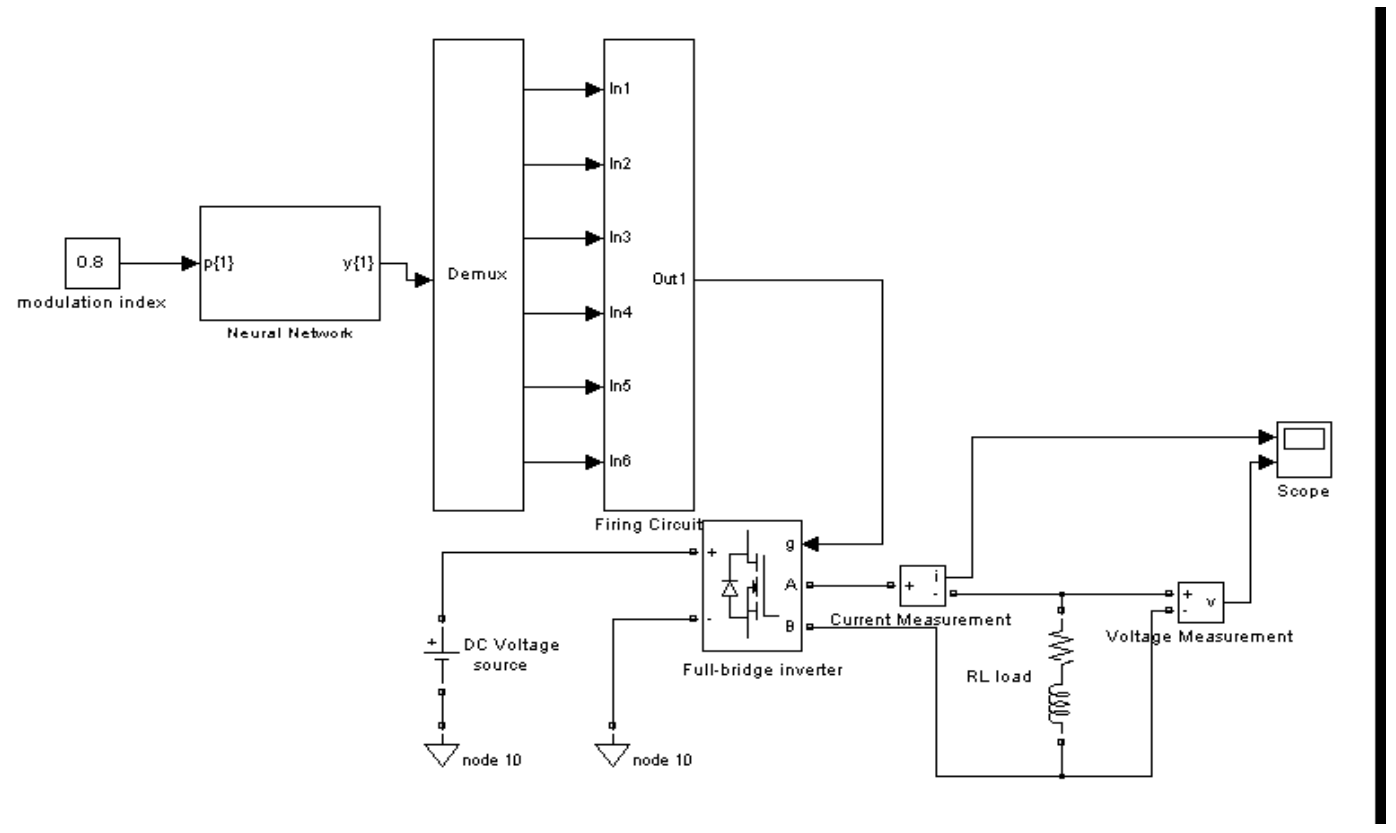


Fig. 4: The Simulink model of full bridge inverter using neural network control with six switching angles

In this model it is assumed that the DC voltage source is $100 \mathrm{~V}$ and the inverter is full bridge inverter with MOSFET switch and the with RL load of $\mathrm{R}=10$ and $\mathrm{L}=10 \mathrm{mH}$. The neural network chip is considered to accept one input (Modulation index) and generates six outputs (switching angles), and have firing circuit to generate firing signals for the inverter depending on the switching angles values.

Fig's ( $5 \& 6$ ) show the voltage and current outputs of the inverter with the value of $\mathrm{M}=0.8$ and their Fast Fourier Transform (FFT) spectrum for the
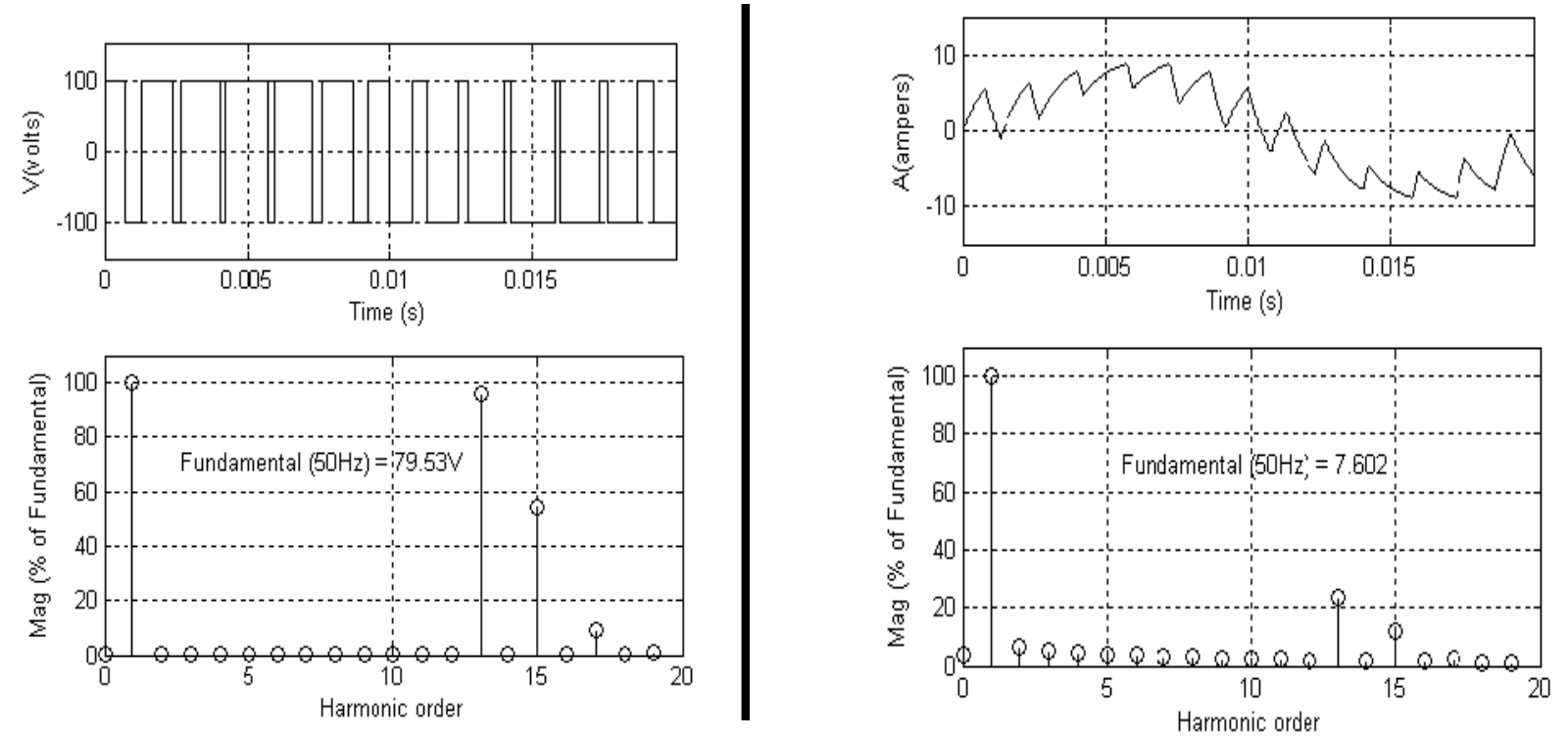
six switching angles circuit in the off-line state.

Fig.5 : The output voltage of inverter and

Fig.6:

The load current and its

Its FFT spectrum with $\mathrm{M}=\mathbf{0 . 8}$ using

FFT

spectrum with $\mathrm{M}=0.8$ using

Neural network control

neural

network control

Figs. ( $7 \& 8)$ show the voltage and current output of the inverter with the value of $\mathrm{M}=0.8$ and their harmonic spectrum for the six switching angles circuit using on line neural network state.
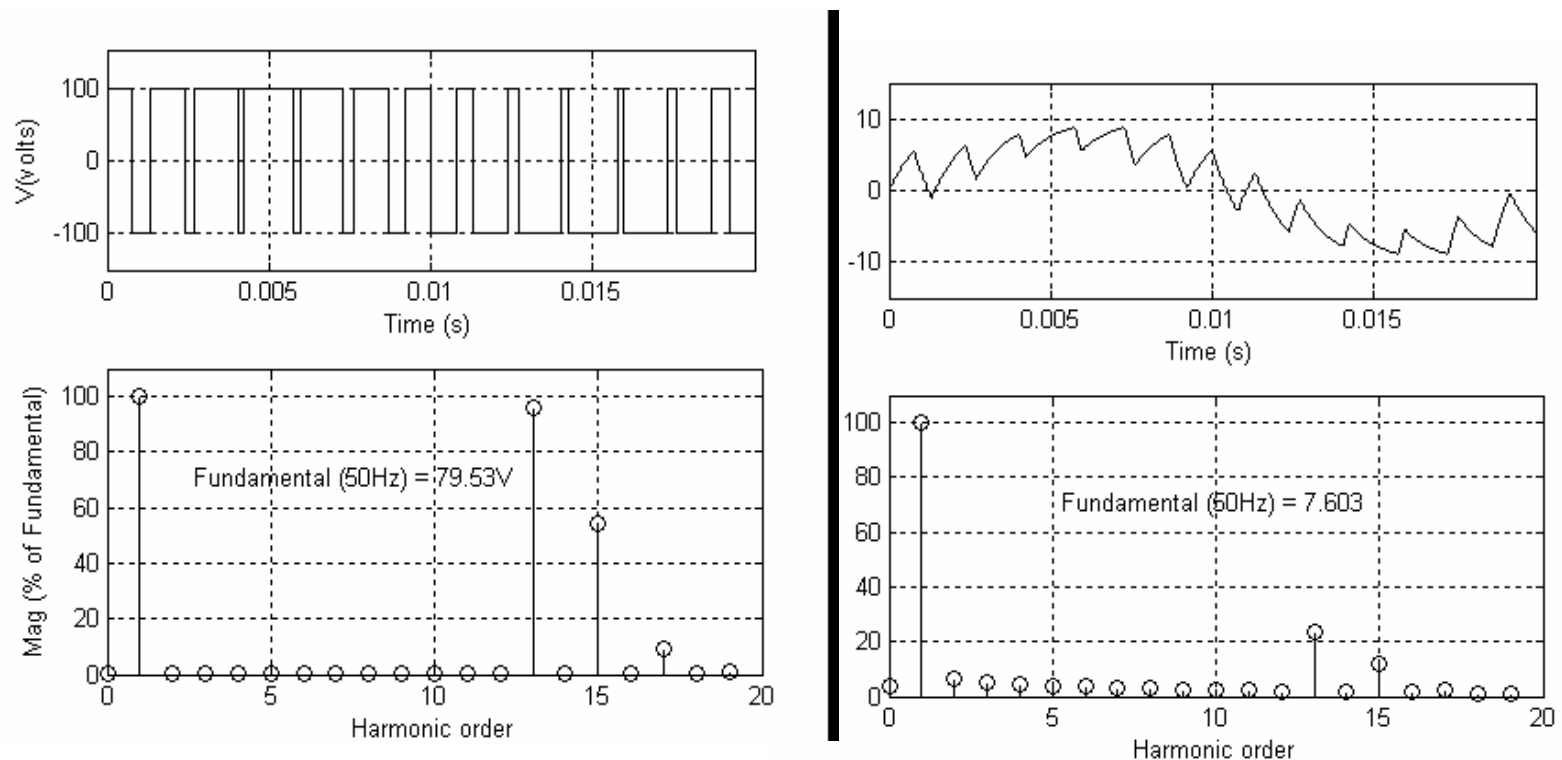

Fig. 7: The output voltage of inverter and

Fig. 8: The load current and its spectrum with
its FFT spectrum with $\mathrm{M}=\mathbf{0 . 8}$ using
neural network control
$\mathrm{M}=\mathbf{0 . 8}$ using

neural network control 


\section{Fuzzy Logic Implementation}

The Fuzzy Logic controller is implemented on selective harmonic elimination PWM to find suitable design to carry out the function of choice and generate switching angles for the firing of the full bridge inverter. Fuzzy Logic algorithm can be implemented using MATLAB/SIMULINK program to achieve the design of the fuzzy logic circuit which will take the place of the neural network circuit in the previous model and Fig. 9 shows the model of full bridge inverter using fuzzy logic controller.

\section{Fuzzy Block Design}

The design of fuzzy logic block depends on the saying that the input is a numeric number and not a human word like (low, high, fast,...). Therefore the membership function may differ from language once, and the output of the block which are also numeric numbers. This is achieved by using Sugeno-type fuzzy inference which accepts this idea and gives the chance to implement the input data and output data. In the Sugenotype fuzzy inference the input membership functions are the same as Mamdani 's inference method but the output membership functions are different from Mamdani in which the membership either constant or Linear, so the Sugeno-type inference is useful for the in hand proposed circuit. The circuit diagram of the fuzzy block is shown in Fig. 9. This

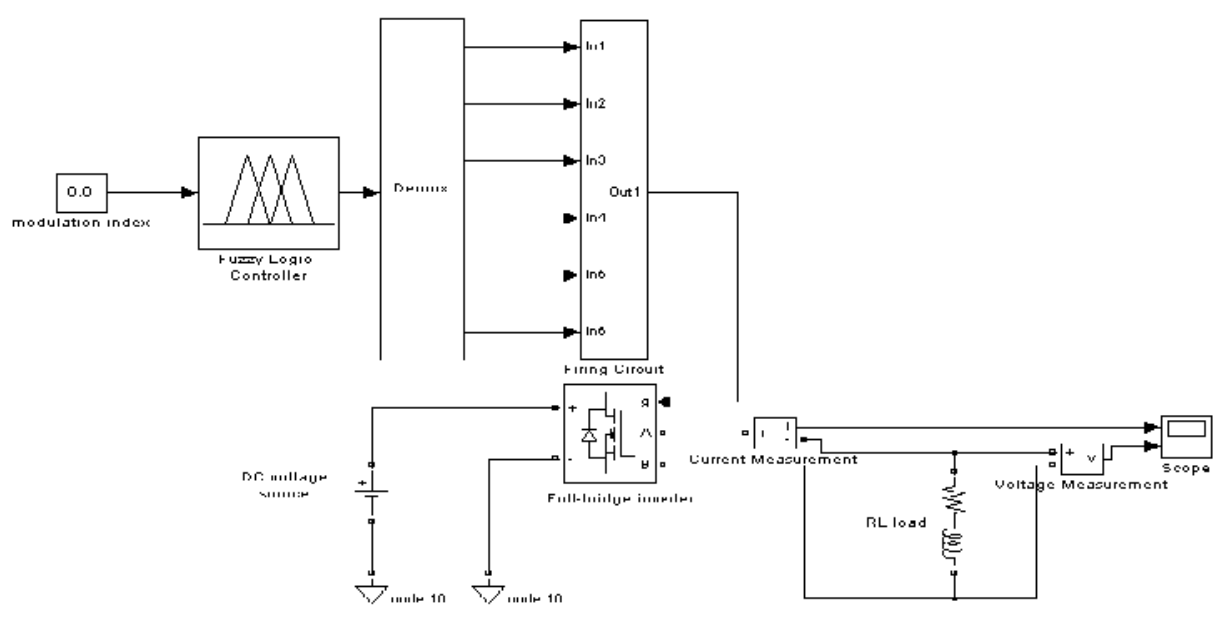

circuit contains one input as 100 membership functions representing 
input data with triangle membership type and can insert the value of each membership function as example [0.1 0.20 .3 , it also includes six output each output contain 100 membership functions representing output data with constant membership type which accepts one numeric value. There are 100 rules that work to combine between the input membership function and the output membership function as (if ....then) rules and these rules are similar to the training process in neural network for learning

Fig. 9: The simulink model of full bridge inverter with fuzzy logic control 
The Simulink model of Fig.9 has been built incorporating the fuzzy logic block of Fig.10 with the necessary rules and membership functions. The model has been implemented to control the firing angles of a six pulse $\mathrm{H}$ bridge inverter. Figs. (11 \& 12) show the results of both voltage and current outputs waveforms and their spectrums of VSI at M=0.8 of fuzzy logic controller model.

Table 1 shows an over all summary of the results, as a sample, given in \% of the fundamental for the selected eliminated harmonics for: off line state, the neuro controller, and the fuzzy logic controller which are used to perform the six switching angles case at two values of $\mathrm{M}$ equal to 0.8 and 1 .

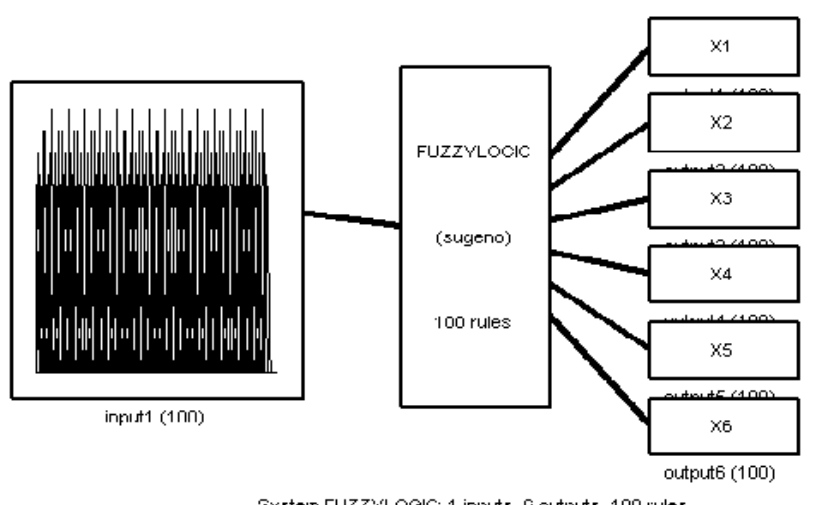

Systen rUZZ'ILOOC: 1 inputs, 0 outputs, 100 rules

Fig. 10: Fuzzy logic system diagram
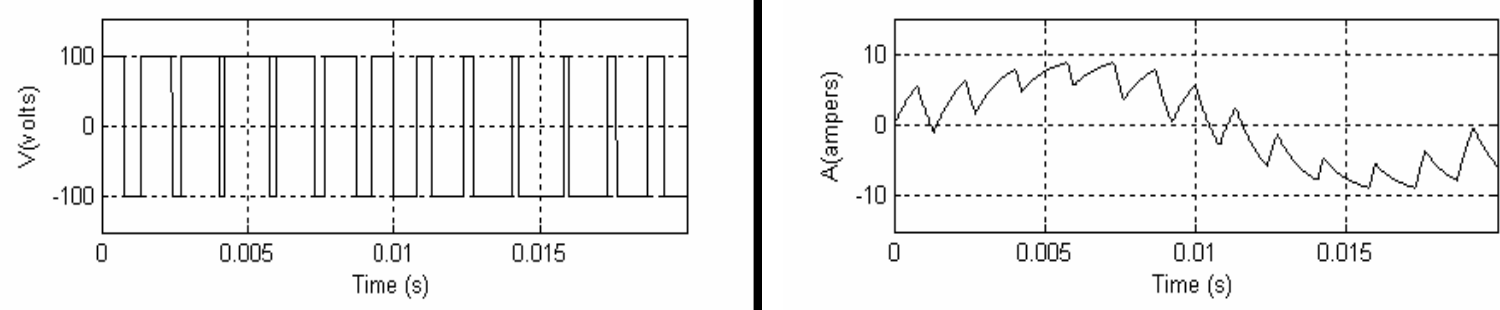
Fig. 11:The output voltage of inverter current and its spectrum with

and its FFT spectrum with $\mathrm{M}=0.8$ neural network fuzzy

using fuzzy logic control circuit.
Fig. 12:The load $\mathrm{M}=\mathbf{0 . 8}$ using

$$
\text { using fuzzy logic control circuit. }
$$

logic control circuit.

\begin{tabular}{|l|l|}
\hline $\begin{array}{c}\text { Type of } \\
\text { circuit }\end{array}$ & Six switching angles \\
\hline
\end{tabular}




\begin{tabular}{|c|c|c|c|c|c|c|c|}
\hline \multicolumn{2}{|c|}{$\begin{array}{l}\text { Type of } \\
\text { control }\end{array}$} & \multicolumn{2}{|c|}{$\begin{array}{c}\text { Off-line } \\
\text { state }\end{array}$} & \multicolumn{2}{|c|}{$\begin{array}{c}\text { Neural } \\
\text { network }\end{array}$} & \multicolumn{2}{|c|}{ Fuzzy logic } \\
\hline \multirow{2}{*}{$\begin{array}{c}\text { No. } \\
\text { harmonic } \\
\text { order }\end{array}$} & \multirow[b]{2}{*}{$\mathbf{M}$} & \multicolumn{6}{|c|}{ Magnitude \% of Fundamental } \\
\hline & & 0.8 & 1 & 0.8 & 1 & 0.8 & 1 \\
\hline $1^{\text {st }}$ & & 99.35 & 99.48 & 99.3625 & 99.47 & 99.35 & 99.98 \\
\hline $3^{\text {rd }}$ & & 0.02 & 0.01 & 0.01 & 0.01 & $\mathbf{0 . 0 3}$ & 0.0 \\
\hline $5^{\text {th }}$ & & 0.01 & 0.02 & 0.05 & 0.01 & 0.01 & $\mathbf{0 . 0}$ \\
\hline $7^{\text {th }}$ & & 0.03 & $\mathbf{0 . 0}$ & 0.05 & $\mathbf{0 . 0}$ & $\mathbf{0 . 0 3}$ & $\mathbf{0 . 0}$ \\
\hline $9^{\text {th }}$ & & 0.02 & 0.01 & 0.04 & 0.02 & $\mathbf{0 . 0 3}$ & 0.005 \\
\hline $11^{\text {th }}$ & & 0.03 & 0.04 & 0.03 & $\mathbf{0 . 0 3}$ & 0.01 & 0.001 \\
\hline
\end{tabular}

Table 1: The comparison results of the different types of control for the magnitude of fundamental and eliminated harmonics

VI. Conclusion

The intelligent methods which are mentioned in this paper are implemented on (SHE PWM) to achieve the function of control instead of using digital signal processing which needs large look-up tables to save large amount of information about the values of modulation index and their corresponding switching angles values, as a result it needs a large memory to obtain high resolution. Therefore the intelligent techniques (neural network \& fuzzy logic) deal with the plant as nonlinear map from input to output side by learning and training the network for neural network and building the rules to regulate the membership functions for fuzzy logic. It ca be concluded that: 
1. From the simulation results using neural network package in MATLAB/SIMULINK program, it is found that the MSE (mean square error) for the training process is small and this refers to the closeness of the calculated output sets to the target sets and makes the new circuit equivalent to the original circuit, and also from the waveforms of the output voltage of the full-bridge inverter and their FFT spectrum like the results for the actual values.

2. the general properties of neural network is the simplicity of building and arranging to achieve the training process of the small sets of input and target and the number of nodes (neurons) in the hidden layer of the network, but for the large sets or for the high number of neurons in hidden layer, the network becomes complex and needs more time to complete the training process, after the training process it will be possible to get the sets of weights and biases which feed the neurons in each layer of the network and builds the new network.

3. For the fuzzy logic the circuit depends on the membership function of input and output and the rules which work to link between the input membership and output membership, and we implementing it on SHE PWM with sugeno fuzzy inference procedure which considers the output set constant and useful for representing the switching angles values, and as for the simulation results of MATLAB/SIMULINK is clear that the fuzzy logic system is accurate as the original circuit, but it differs from the neural network and it does not need time to train such as the neural network.

4. The neural network can realize any number of inputs and outputs for training and generating the patterns, but the fuzzy logic can only represent a limited number of inputs and outputs due to the increasing complexity and the number of the rules required which make it difficult.

\section{References}

[1] Zainal Salam. "DC to AC conversion (inverters)" Power Electronics $\begin{array}{llll}\text { and Drives } & \text { (Version } 2002 .\end{array}$ encon.fke.utm.my/courses/see_5433/inverter.pdf

[2] Mohammed H. Rashid. "Power Electronics" Prentice-Hall of India Private Limited, Second Edition, 1994(Book). 
[3] Bimal K. Bose. "Modern Power Electronics and AC Drives" Pearson education, Second Edition, 2003 (Book).

[4] Siriroj Sirisukprasert. "Optimized Harmonic Stepped-Waveform for multilevel inverter” M. Sc. Thesis, Blacksburg Virginia University 1999.

[5] Mohammed K. Al-shuqfa. "Investigation of some Uninterruptible Power Supply (UPS) Concepts” M.Sc.Thesis, University of Mosul,2001.

[6] Jacek M. Zurada. "Introduction to Artificial Neural Systems" Jaico Publishing House, 1996 (Book).

[7] Jyh-Shing Roger Jang. "Neuro-Fuzzy and Soft Computing: A Computational Approach to Learning and Machine Intelligence" et al, Prentice-Hall, 1996 (Book).

[8] Insop Song. "Fuzzy Logic and Neural Network Controller" ISSN 0358-5654, University of Waterloo, SD558 Fuzzy Logic \& Neural Network, Winter 2002.

[9] Robert Fullér. "Neural Fuzzy Systems" ISBN 951-650-624-0, ISSN 0358-5654, Åbo 1995.

[10] M. Mohaddes, P.G. Mclaren, A.M.Gole. "Control of Optimal PWM Voltage Source Inverter using Sigmoid and Picewise Linear Artificial Neural Network" Graduate Student conference GRADCON'98 Winnipeg, MB,Canada,1998.

\section{Appendix}

Samples values of modulation index and their corresponding switching angles values for six switching angles(off-line state)

\begin{tabular}{|r|c|c|c|c|c|c|}
\hline $\begin{array}{r}\text { Iulation n } \\
\text { ndex (M) }\end{array}$ & $\alpha_{1}\left(\mathrm{rad}_{.}\right)$ & $\alpha_{2}(\mathrm{rad})$. & $\alpha_{3}\left(\mathrm{rad}_{.}\right)$ & $\alpha_{4}(\mathrm{rad})$. & $\alpha_{5}(\mathrm{rad})$. & $\alpha_{6}(\mathrm{rad})$. \\
\hline $\mathbf{0 . 0 1}$ & $\mathbf{0 . 2 4 1 9}$ & $\mathbf{0 . 4 8 2 8}$ & $\mathbf{0 . 7 2 5 8}$ & $\mathbf{0 . 9 6 5 6}$ & $\mathbf{1 . 2 0 9 4}$ & $\mathbf{1 . 4 4 8 8}$ \\
\hline
\end{tabular}




\begin{tabular}{|c|c|c|c|c|c|c|}
\hline 0.05 & 0.2431 & 0.4808 & 0.7789 & 0.9616 & 1.2139 & 1.4439 \\
\hline 0.1 & 0.2444 & 0.4774 & 0.7326 & 0.9563 & 1.2193 & 1.4379 \\
\hline 0.15 & 0.2456 & 0.4742 & 0.7361 & 0.9509 & 1.2247 & 1.4317 \\
\hline 0.2 & 0.2467 & 0.4708 & 0.7393 & 0.9452 & 1.2299 & 1.4255 \\
\hline 0.25 & 0.2476 & 0.4673 & 0.7424 & 0.9393 & 1.2349 & 1.4192 \\
\hline 0.3 & 0.2485 & 0.4636 & 0.7451 & 0.9332 & 1.2398 & 1.4128 \\
\hline 0.35 & 0.2492 & 0.4598 & 0.7476 & 0.9269 & 1.2446 & 1.4062 \\
\hline 0.4 & 0.2498 & 0.4558 & 0.7498 & 0.9203 & 1.2491 & 1.3995 \\
\hline 0.45 & 0.2503 & 0.4516 & 0.7517 & 0.9133 & 1.2535 & 1.3926 \\
\hline 0.5 & 0.2506 & 0.4472 & 0.7531 & 0.906 & 1.2576 & 1.3855 \\
\hline 0.55 & 0.2507 & 0.4426 & 0.7541 & 0.8983 & 1.2614 & 1.378 \\
\hline 0.6 & 0.2506 & 0.4378 & 0.7545 & 0.8901 & 1.2648 & 1.3702 \\
\hline 0.65 & 0.2503 & 0.4328 & 0.7543 & 0.8812 & 1.2676 & 1.3618 \\
\hline 0.7 & 0.2497 & 0.4275 & 0.7533 & 0.8717 & 1.2698 & 1.3527 \\
\hline 0.75 & 0.2489 & 0.4219 & 0.7513 & 0.8613 & 1.2708 & 1.3426 \\
\hline 0.8 & 0.2477 & 0.4158 & 0.7479 & 0.8496 & 1.2702 & 1.3307 \\
\hline 0.85 & 0.2459 & 0.4092 & 0.7428 & 0.8364 & 1.2665 & 1.3158 \\
\hline 0.9 & 0.2435 & 0.4018 & 0.735 & 0.8206 & 1.257 & 1.2951 \\
\hline 0.95 & 0.2398 & 0.3926 & 0.7221 & 0.8 & 1.232 & 1.2592 \\
\hline 1 & 0.2298 & 0.3751 & 0.6869 & 0.7578 & 1.136 & 1.1548 \\
\hline
\end{tabular}

